\title{
Toward More Operational Dynamic Capabilities Concept: Possible Contribution of the Dynamic Enterprise Construct
}

\author{
Mojca Duh ${ }^{1}$ \\ ${ }^{1}$ Faculty of Economics and Business, University of Maribor, Slovenia \\ Correspondence: Mojca Duh, Faculty of Economics and Business, University of Maribor, Razlagova 14, \\ Maribor, Slovenia. E-mail: mojca.duh@uni-mb.si
}

Received: February 16, 2013

Accepted: March 7, 2013

Online Published: April 14, 2013

doi:10.5539/ijbm.v8n9p24

URL: http://dx.doi.org/10.5539/ijbm.v8n9p24

\begin{abstract}
The main purpose of the research is to provide some new cognition toward more operational dynamic capability concept based on the enterprise's life cycle concept and a dynamic enterprise construct. The logic of ten dynamic enterprise's characteristics is followed and propositions are developed. These propositions are providing basis for development of empirical testing as well as indicating conditions for building and sustaining enterprise's dynamics. An integral and holistic governance and management approach is of crucial importance for implementing enterprise's major orientation toward "dynamics". This orientation should be incorporated in goals and objectives at all hierarchical levels of management process; that is in enterprise's vision, mission, and strategies as well as in operative goals and objectives of an enterprise.
\end{abstract}

Keywords: dynamic capability, dynamic enterprise, life cycle, management, resource-based view, exploration, exploitation, ambidexterity

\section{Introduction}

The new competitive landscape is characterized by rapid changes and increasing globalization (Hoskisson, Hitt, Wan \& Yiu, 1999) thus influencing the average period for which enterprises are able to sustain competitive advantage (Wiggins \& Ruefli, 2005). According to many research findings this period has decreased over time and for this reason a competitive advantage in hypercompetitive environments can only be enjoyed for limited period of time (e.g., Ambrosini \& Bowman, 2009). Therefore, sustained competitive advantage is increasingly a matter not of a single advantage maintained over time but more a matter of achieving over time a sequence of advantages (Barreto, 2010). This situation implies that enterprises should be managed in such a way that they can build successive temporary advantages by effectively responding to rapid environmental changes-it means that enterprises must be "dynamic". One of the recent theoretical concepts that address the problem of enterprise's dynamics within strategic management field is the "dynamic capabilities approach" developed by Teece, Pisano and Shuen (1997; also Teece, 2007). Unlike earlier approaches (e.g., Porter’s competitive forces framework, strategic conflict approach using game theory, and resource-based view) which were largely static in nature, the dynamic capabilities concept explicitly acknowledges that enterprises need to adjust to market and technological changes by reallocating assets and learning new skills (Harreld, O’Reilly \& Tushman, 2007). As major research goal of the dynamic capabilities approach Teece (2007) exposed an attempt to "... provide an umbrella framework that highlights the most critical capabilities management needs to sustain the evolutionary and entrepreneurial fitness of the business enterprise" (p. 1322). Finding answers to the question on how to sustain competitive advantage and long-term performance was also triggering Pümpin and Prange (1995) who introduced the idea of a dynamic enterprise. The authors based their research on evolutionary theory and strategic management theory, thus building their concept of a dynamic enterprise on their model of enterprise's life cycle.

The main goal of our research is to conduct a comparable analysis of the dynamic enterprise construct developed by Pümpin and Prange (1995) and the dynamic capabilities concept (mainly the Teece's framework and some recent research within dynamic capabilities approach), thus demonstrating the interrelationship between these two constructs and providing some new cognition toward more operational concept which would offer a platform for empirical testing. The reasons for our research, which is of theoretical nature, are twofold. First, there are many criticism stating that the dynamic capabilities approach is conceptually vague and 
tautological (e.g., Eisenhardt \& Martin, 2000), resistant to observation and measurement (Kraatz \& Zajac, 2001) and lack of empirical grounding (Barney, Wright \& Ketchen, 2001; Eisenhardt \& Martin, 2000). Second, some authors questioned the term "dynamic capability" itself; for example, Schreyögg and Kliesch-Eberl (2007) suggested that dynamic capabilities are being build on "... two contradictory notions of logic at the same time: reliable replication and continuous change - two dimensions that hardly mix" (pp. 922-923). Barreto (2010) exposed the dangerous of hindering the progress of this research field due to the distinct definitions of the construct, complex and disconnected research. Within the context of matching the demands of rapid changing environments we find the dynamic enterprise construct (Pümpin \& Prange, 1995) as a useful concept for broadening our understanding on how enterprises can achieve and sustain dynamics.

The paper is divided into four chapters. Following the introductory chapter, the second chapter discusses the origins as well as some recent research findings of the dynamic capabilities approach. The third chapter discusses the model of enterprise's life cycle on which Pümpin and Prange (1995) built the concept of a dynamic enterprise. In the fourth chapter we follow the logic of a dynamic enterprise's characteristic linking both constructs (i.e., dynamic capabilities and dynamic enterprise). The last chapter outlines the most significant conclusions and suggests directions for future research.

\section{Dynamic Capabilities Approach}

The dynamic capabilities concept has been introduced as an extension of the resource-based view (RBV) as one of the most promising approaches in dealing with the question on how enterprises can sustain superior performance in changing environments. Teece et al. (1997) introduced the concept and published it in the article thus evoking the research community (for references see Barreto, 2010). The RBV explains the competitive heterogeneity by stating that close competitors differ in their resources and capabilities in important and durable ways. According to RBV sustained competitive advantage derives from enterprise's resources and capabilities that are valuable, rare, imperfectly imitable, and not substitutable (Barney et al., 2001; Helfat \& Peteraf, 2003). However, the reliance on a specific set of nurtured capabilities has being under question in environments characterized by rapid changes of conditions. Therefore, emphasis has shifted to the ability to change and quickly develop new capabilities as prerequisite for competitive advantage. The notion "dynamic" has been used to address the continuous renewal of capabilities, thereby matching the demands of changing environments (Schreyögg \& Kliesch-Eberl, 2007, p. 914).

Teece et al. (1997) define dynamic capabilities as “... the firm's ability to integrate, build, and reconfigure internal and external competences to address rapidly changing environments... " (p. 516); dynamic capabilities “... include difficult-to-replicate enterprise capabilities to adapt to changing customer and technological opportunities” (Teece, 2007, pp. 1319-1320). For analytical purpose Teece (2007) disaggregated dynamic capabilities "... into the capacity (1) to sense and shape opportunities and threats, (2) to seize opportunities, and (3) to maintain competitiveness through enhancing, combining, protecting, and when necessary, reconfiguring the business enterprise's intangible and tangible assets” (pp. 1319-1320). Many other definitions and concepts of dynamic capabilities have been introduced after the introduction of the idea in 1997 by Teece et al. (for overview of different definitions see Barreto, 2010). The review of research indicates that in many definitions a dynamic capability is viewed as a multidimensional aggregate construct, where dimension are themselves constructs (e.g., Barreto, 2010); some authors even distinguish between different levels of capabilities (e.g., Winter, 2003). Many authors (e.g., Winter 2003) point out that dynamic capability should not be seen as ad hoc problem solving or crisis fighting; for example Zollo and Winter (2002) state that dynamic capabilities are structured and persistent. According to O'Reilly and Tushman (2007) dynamic capabilities “... are at the heart of the ability of a business to be ambidextrous - to compete simultaneously in both mature and emerging markets to explore and exploit” (p. 12). Other authors point to the definitional problems not only within the dynamic capabilities approach but as well as within the RBV. Namely, the RBV and its associated terminology lack clear definitions (Wang \& Ahmed, 2007) and has limited empirical support (Ambrosini \& Bowman, 2009). These could be also one of reasons for the mixed use and different interpretation of dynamic capabilities. Numerous definitions of dynamic capabilities shows that additional research is needed in order to make more clear definition of what actually dynamic capabilities are. This is highly needed due to the lack of empirical studies (Ambrosini \& Bowman 2009) and many criticisms about the empirical testing of the construct (e.g., Barreto, 2010; Wang \& Ahmed 2007) which would need clearer framework and definition of measurable variables.

\section{Pümpin and Prange's Concept of the Enterprise's Lifecycle and a Dynamic Enterprise}

Pümpin and Prange (1995) introduced the idea of a dynamic enterprise within their model of enterprise's development. They combine evolutionary theory and strategic management theory and developed their own 
developmental model of an enterprise based on the life cycle concept. The proposed developmental stages within the model are described by four typical enterprise's configurations, entitled a pioneer enterprise, a growing enterprise, a mature enterprise and an enterprise in turnover. According to Pümpin and Prange (1995), the implemented business opportunities influence the enterprise's developmental path. Since business opportunities follow their own life cycle which leads to a decline stage, it is essential for an enterprise to search for and discover new business opportunities. Pümpin and Prange (1995) point to the dangerousness of tendencies of enterprises toward a mature stage (i.e., a mature enterprise) and argue the need of revitalization and dynamics of an enterprise. Namely, an enterprise at least at the beginning of a mature stage shows numerous strengths such as (Pümpin \& Prange, 1995): competent management, low production costs due to the economy of scale, large assets base, knowledge and experiences regarding markets, possession of technologies and distribution channels, established and strong relationships with customers, suppliers and government, and stability of financial outcomes. However, later during the mature stage weaknesses become stronger and if not adequately managed can threaten the enterprise's existence. Pümpin and Prange (1995) pointed specially to the following weaknesses: lack of flexibility needed for adjusting to environmental changes, numerous obstacles to innovations (e.g., cultural obstacles are specially dangerous), increasing resistance towards risk and short-term management orientation with the focus on quantity, entrepreneurial oriented employees are undesirable, top management is losing insight into markets, struggles among managers for leading positions within the enterprise, and bureaucracy.

Similarly, some other authors call attention of weaknesses of established enterprises which are specially recognized within the dynamic capabilities framework. For example, Schreyögg and Kliesch-Eberl (2003) argue that in environments characterized by rapid changes organizational capabilities may easily invert from a strategic asset into a strategic burden due to path-dependency and lock-in, structure inertia and resources commitment. Therefore, enterprises are confronted with a dilemma: on one hand, they have to develop reliable patterns of selecting and linking resources in order to attain superior performance and competitive advantages, on the other hand, these efforts represent a considerable risk of becoming lock into exactly these capabilities. Similarly, Teece (2007) argues that as the enterprise grows, it has more assets to manage and to protect against malfeasance and mismanagement. Shirking to responsibility, free riding, the strategic manipulation of information, and internal self-satisfaction are the issues that established enterprises confront continuously. Over time successful enterprises develop hierarchies as well as rules and procedures that begin to present obstacles for interactions and behaviors unnecessarily. Except in very stable environments, such rules and procedures are likely to require constant changes in order to sustain superior performance. In particular incumbent enterprises tend to avoid "... radical competency-destroying innovation in favor of more incremental competency-enhancing improvements” (Teece, 2007, p. 1327). The existence of many standard procedures, established capabilities, complementary assets, as well as of administrative routines can create obstacles for innovation.

Pümpin and Prange (1995) suggests that an enterprise should be managed in such way that it never "progresses" to a mature stage. They introduce the fifth type of enterprise's configuration, labeled as "a dynamic enterprise". A dynamic enterprise is a "combination" of a pioneer and a growth enterprise where the management efforts should be triple. First, reducing tendencies towards a mature phase/enterprise; second, continuous seeking and gaining new business opportunities for which pioneering features are needed; and third, developing the ability for multiplication of business opportunities, which is one of the main characteristics of a growing enterprise. Since the concept of a dynamic enterprise is based on the premise that the combination of a pioneer and a growing enterprise's characteristics/elements enables an enterprise to "avoid" a mature stage, we developed the following proposition:

Proposition 1: The presence of elements of a pioneer and a growing enterprise/phase positively influence the ability of an enterprise to build and sustain dynamics.

We can expect that enterprises, where elements of a pioneer and a growing enterprise/phase prevail, possess necessary conditions for building dynamics. Pümpin and Prange (1995) developed the methodology for assessing the presence of elements of a pioneer and a growing enterprise as well as of a mature enterprise and an enterprise in turnover. Therefore, by assessing the presence of elements of a pioneer and a growing enterprise, the management can create necessary measures towards building enterprise's dynamics. Since, the information on the presence of elements of a mature and a turn-over phase can also be provided to the management, the measures can be taken in order to avoid progress in a mature or even a turn-over stage. 


\section{Dynamic Enterprise in the Light of the Dynamic Capabilities Approach}

The main particularities of a dynamic enterprise are according to Pümpin and Prange (1995) the following ones: seeking and gaining new and attractive business opportunities, multiplication of systems and processes, development of differentiated cultures, flexible legal regulations, development of dynamics promoters, development of strategic origins of success, flexible adaptation of structural and process organization, limiting of the leadership system to a reasonable optimum, orientation toward the individual and time orientation. These characteristics, which represents the important conditions for building and sustaining dynamics of an enterprise (see also Phan, 2006), are discusses in the light of the dynamic capabilities approach.

\subsection{Seeking and Gaining New and Attractive Business Opportunities}

The main characteristic of a dynamic enterprise is directing all its efforts towards finding attractive business opportunities. As opposed to a mature enterprise, a dynamic enterprise is aware of the business opportunity life cycle; therefore, it constantly seeks new opportunities. This searching should be carried out within the visionary definition of an enterprise, which is explaining the direction of enterprise's development in the future (Pümpin \& Prange, 1995).

This notion of importance of seeking and gaining new business opportunities as an important element of enterprise's ability to adapt to environmental changes is consistent with Teece's (2007) argumentation that "... to sense and shape opportunities and threats...” (p. 1322) are one of the most important capabilities of an enterprise. It consists of scanning, creation, learning, and interpretive activity. According to Pümpin and Prange (1995) the seeking of opportunities cannot be merely analytical. Contrary, it should be going in constant interactions with relevant groups of stakeholders. With other words: a dynamic enterprise is trying to discover new business opportunities with constant testing. Especially in this, it shows the characteristics of a pioneer enterprise. Similarly, Teece (2007) points out that in order to identify and shape opportunities not only investments in research activities are needed but also the probing and re-probing of customer needs and technological possibilities, understanding latent demand, the structural evolution of industries and markets, and likely supplier and competitor responses. Based on the above stated arguments we developed the following proposition:

Proposition 2: Management endeavor for seeking and gaining new and attractive business opportunities positively influences enterprise's dynamics.

\subsection{Multiplication of Systems and Processes}

Multiplication is the main characteristic of growing enterprise. Such an enterprise discovered one or more attractive opportunities and is exploiting them to greatest extent. This is an important characteristic of a dynamic enterprise as well. As soon as it discovered attractive opportunity, it is striving to exploit it and if possible taking over the leading position on the market. Multiplication of systems and processes in a dynamic enterprise requires the implementation of several adequate measures such as standardization and optimization of costs (Pümpin \& Prange, 1995).

Similarly, Teece (2007) argues that one of the most important capabilities of an enterprise is seizing opportunities which “... involves maintaining and improving technological competences and complementary assets and then, when opportunity is ripe, investing heavily in particular technologies and designs most likely to achieve marketplace acceptance” (p. 1326). As an important part of seizing activity Teece (2007) suggests selecting product architectures and business models, selecting enterprise boundaries, managing complements and "platforms" and avoiding bias, delusion, deception, and hubris. Therefore, the following proposition was developed:

Proposition 3: Management endeavor for multiplication of systems and processes positively influences enterprise's dynamics.

\subsection{Development of Differentiated Cultures}

The main attention of a dynamic enterprise should be devoted to the parallel development of two different cultures. First, seeking and searching for new business opportunities demands culture where creativity and innovativeness are stimulated. The main characteristics of such culture are individualism and entrepreneurship (i.e., intrapreneurship). Second, multiplicative exploitation of attractive business opportunities demand a culture which is oriented towards realization of defined goals and objectives. Since the time is important factor (for taking over strong market position before competitors), there is little room for individual innovations. The only ambition should be the successful realization of already started problem solving. These two cultures are very different, and it is difficult to avoid conflict while implementing both. The management of a dynamic enterprise should therefore make a constant effort to explain these two different necessities (Pümpin \& Prange, 1995). 
Teece (2007) addresses the role of culture within the dynamic capability approach by giving an important role to top management who "... through its action and its communication has a critical role to play in garnering loyalty and commitment and achieving adherence to innovation and efficiency as important goals” (p. 1334). However, the author does not discuss the issues of culture, commitment and loyalty any further. He leaves their full integration to other researchers. However, we find important within the culture context Teece's (2007) discussion on the problem of different "nature" of two fundamental capabilities (i.e., sensing and seizing) by quoting March (1996, 2006) observations of exploitation and exploration. Namely, March (1996) finds exploration and exploitation as being both necessary for adaptation, but he also recognizes that the adaptation is continuously threatened by the tendency of each to extinguish the other. Therefore, specifying the optimal mix of exploitation and exploration is difficult or impossible. Similarly, Teece (2007) argues that simultaneous pursuit of exploration and exploitation is difficult. In author opinion, incompatibilities flow from the fact that exploration and exploitation compete for resources and that the mindsets and organizational routines needed are different. Teece $(2007,1343)$ sees possible solution in having different organizational units or different parts of organizational unit specialized to some degree on sensing as compared to seizing. However, research findings (e.g., Bierly \& Daly, 2007; Gibson \& Birkinshaw, 2004) has provided evidence for enterprises' ability to simultaneously (i.e., harmonic ambidexterity or so-called contextual ambidexterity) or sequentially (i.e., cyclical ambidexterity) pursue exploitation and exploration within an independent business unit. Especially the contextual ambidexterity is strongly linked to organizational culture (e.g., Simsek, Heavey, Veiga, \& Souder, 2009); in the recent research Wang \& Rafiq (2012) conceptualized 'ambidextrous organizational culture' as being pre-condition for contextual ambidexterity where simultaneously pursuing of exploration and exploitation is in the centre.

Proposition 4: Management endeavor for developing ambidextrous organizational culture positively influences enterprise's dynamics.

\subsection{Simple and Flexible Legal Regulations (Such as Statutes)}

The constant sensing and shaping of opportunities requires high flexibility of an enterprise regarding participation in ownership of other enterprises (e.g., important for growing enterprises) as well as governance and management structure which has to be flexible and meet developmental needs of an enterprise. Therefore, such internal legal regulation (of course within national legal framework) are needed which enables flexible adaptation of governance and management structure when needed (Pümpin \& Prange, 1995).

Teece (2007) does not explicitly address the legal issues of governance and management structure. However, we believe that simple and flexible legal regulations of governance and management structure are of crucial importance for building and sustaining enterprise's dynamics. According to Müller-Stewens and Lechner (2005) the governance and management structure importantly influence company's performance and competitive position. Research (e.g., Wheelen \& Hunger, 2012) show that the role of the board of directors in the strategic management is going to be more active in the future since boards are getting more involved not only in reviewing and evaluating enterprise's strategy but also in its creation. According to Wheelen and Hunger (2012) even though "... neither the composition of boards nor the board leadership structure has been consistently linked to firm financial performance, better governance does lead to higher credit ratings and stock prices” (p. 105). Based on these argumentations we developed the following proposition:

Proposition 5: Simple and flexible legal regulations of governance and management structure positively influence enterprise's dynamics.

\subsection{Development of Dynamics Promoters}

In general, the critical role in a dynamic enterprise belongs to the entrepreneurial thinking and functioning. This is due to the fact, that long-term development and success of an enterprise is possible only if entrepreneurial initiatives are developed at all enterprise's levels and constant seeking of achieving very demanding goals is present. Therefore, it is important to develop the promoters of dynamics which is the main task of enterprise's top-management. In order to avoid the dangerous of "entrepreneurial blindness", it is useful to bring the dynamic promoters from outside the enterprise. This "fresh blood" brings changes, and prevents too great comfortability in thinking and handling as well as help to prevent from the threat of bureaucracy (Pümpin \& Prange, 1995).

Similarly, Teece (2007) call attention to the dangerous of “entrepreneurial blindness". In author's opinion incumbent enterprises which possess fixed assets may tend to limit their new investments to innovations that are "close-in" to the existing asset base. They tend to narrowly focus search activities to exploit established technological and organizational assets. This effect makes it difficult for these enterprises to see potential radical 
innovation. In addition, incumbent enterprises tend to frame new problems in a way that is consistent with the enterprise's current knowledge base, assets, and established problem-solving and business model. This second effect means that managers may not successfully address opportunities or potential innovations even when they do recognize them. O'Reilly and Tushman (2007), who embed the notion of ambidexterity in the dynamic capabilities framework, call attention to research which shows that managers are more sensitive to threats than opportunities, thus potentially create the difficulties of incumbent senior management teams in relation to sensing. Schreyögg and Kliesch-Eberl (2003) use socialization mechanisms for explaining capabilities persistence in the face of changing environmental demands. Namely, managers become socialized into the belief system in which these capabilities are embedded. Socialization into belief systems that take for granted the current capability pattern is likely to mobilize cognitive and emotional resistance against critical signals indicating the demand for a shift in the familiar patterns of acting. They become reluctant to acknowledge the need for changing a once good problem-solving approach. Even when they are aware of the need to change and willing to change capabilities, the hidden imprints of the capability pattern may lead them to look for alternatives only in the neighborhood of the current practices.

Teece (2007) suggests participation of individuals at the board level who would observe whether the top management team is sufficiently "dynamic". In author's opinion, the replacement of the CEO and other members of top management team are very important to do, if they demonstrate weak sensing, seizing, and reconfiguration capabilities. Studies indicate that outsider managers with an entrepreneurial approach have a positive effect on organizational restructuring since they are more likely to create awareness of the need to change within an enterprise (Dixon, Meyer \& Day, 2010). Teece (2007) points out that maintaining dynamic capability require entrepreneurial management who "... has little to do with analyzing and optimizing. It is more about sensing and seizing - figuring out the next big opportunity and how to address it...” (p. 1346). This could be achieved by introducing "dynamic promoters" in an enterprise as proposed by Pümpin and Prange (1995).

Based on the above stated arguments we built the following proposition:

Proposition 6: The introduction of outside promoters of dynamics positively influences enterprise's dynamics.

\subsection{Development of Strategic Origins of Success}

The management of an enterprise demands special knowledge, skills, competences and abilities to be built and/or acquired in order to create conditions for enterprise's dynamics, thus enabling enterprise to adapt and change permanently. The very demanding synthesis of management concepts of a pioneer and a growing enterprise is needed for which constant inflow of energy in the form of learning, additional training and selection (i.e., hiring and dismissing) of human resources is needed in order to maintain the expertise of employees on the highest level (Pümpin \& Prange 1995, 249-250).

Similarly, Teece (2007) as well as O’Reilly and Tushman (2007) point to the importance of knowledge and learning for sensing and seizing opportunities as well as intangible assets being critical to enterprise success; the creation of learning, knowledge-sharing, and knowledge-integrating procedures is likely to promote ambidexterity and is a key (micro) foundation of dynamic capabilities. Dynamic capabilities are created by organizational learning (e.g., Eisenhardt \& Martin, 2000) in the co-evolution process of past experiences, knowledge articulation and knowledge codification processes (e.g., Zollo \& Winter, 2002). The ability to learn is besides the ability to change among the most important capabilities that a firm can possesses (Barney et al., 2001). Therefore, the governance and incentive structures should be developed to enable learning and the generation of new knowledge (Teece, 2007). Based on the previous stated arguments the following proposition was developed:

Proposition 7: Management endeavor for enabling learning and generation of new knowledge positively influences enterprise's dynamics.

\subsection{Flexible Adaptation of Structure and Process Organization}

Another demanding role is linked to organization. In a dynamic enterprise, the decentralization should be in the center-developing small, flexible units. Therefore, there is the constant need to adapt organization (also with radical changes) in order to prevent the creation of kingdoms and principalities (Pümpin \& Prange, 1995).

Similarly, Teece (2007) points to decentralization that must be pursued as enterprises expand, otherwise flexibility and responsiveness will erode; decentralization brings top management closer to new technologies, the customer and the market. One of widely recognized form of restructuring as enterprises grow is the adoption of the multidivisional form, which Pümpin and Prange (1995) find as an adequate structure for needed flexibility of growing enterprise. This involves decomposition and the devolution of decision rights to quasi-independent 
profit centers. Teece (2007) specially exposes that in rapid changing environments organizational units must have considerable autonomy in order to make decisions rapidly; however, units must also remain connected to activities that have to be coordinated. Achieving and implementing this is in author's opinion an important micro foundation of dynamic capabilities. Therefore, the following proposition was developed:

Proposition 8: Management endeavor for decentralization in expanding enterprise positively influences enterprise's dynamics.

\subsection{Limiting the Leadership System to Reasonable Optimum}

Regarding the leadership systems there should be the following motto put into practice »as simple as possible«. The leadership system should be improved from time to time, as well as it should be made simpler. The leadership system must be flexible and adjusted to the particular circumstances. Pümpin and Prange (1995) specially address the issue of suitable information system where we should always put on the first place the usefulness of information for the end user.

Within the information system context, Teece (2007) call attention to the problem of information decay as information moves up and down in the management hierarchy; therefore, enterprises must create mechanisms and procedures to keep management informed. Management must find methods and procedures to peer through uncertainty and gain insight. This involves gathering and filtering technological, market, and competitive information from both inside and outside the enterprise, making sense of it, and figuring out implications for action.

Proposition 9: Management endeavor for developing simple and flexible leadership system positively influences enterprise's dynamics.

\subsection{Orientation towards Individual}

Employees, specially their qualification, motivation, flexibility and creativity are critical for the enterprise's success. Therefore, the modern concepts of human resource management should be used and special importance should be attached to open communication throughout the enterprise, holistic employee development, innovative and flexible reward systems, as well as communication of common goals (Pümpin \& Prange, 1995).

Similarly, Teece (2007) indicates the importance of building loyalty and commitment for seizing opportunities. According to the author there is the role of leadership in making quality decisions, communicating goals, values and expectations, while also motivating employees and other constituencies. Organizational identification and commitment can dramatically increase an enterprise's performance.

Proposition 10: Management endeavor for introducing the up-to date concepts of human resources management positively influences enterprise's dynamics.

\subsection{Time Orientation}

Critical factor of successful seeking and gaining of new (business) opportunities is time. Those enterprises which acquire new opportunities first are especially successful. Time ("being first") is also of great importance in acquiring strategic position when the opportunity is in the growth stage. Thus, a clear sequence of business priorities must be defined and considered in personal time management of employees and management, as well as time oriented culture should help to take advantage of the factor "time” (Pümpin \& Prange, 1995).

Similarly, Barreto (2010) points out the importance of timing of the decisions regarding the modification of the resource base. The author finds the prove for his assertions of propensity to make timely decisions in the work of Eisenhardt and Martin (2000) who suggested that the potential for long-term competitive advantage lies in the ability to change existing resources "sooner" and in the early work of Teece et al. (1997) who assigned the importance to the ability of quickly accomplishing reconfiguration and transformation ahead of competitors.

Proposition 11: Management endeavor for making timely decisions positively influences enterprise's dynamics.

All eleven propositions developed should be regarded from two perspectives. On one hand, these propositions provide basis for development of empirical testing which should take the form of qualitative case studies due to the complexity of phenomenon studied. According to Lambrecht and Lievens (2008) “... the case-study method allows us to elucidate a subject from different perspectives” (p. 299). Many authors (e.g., Ambrosini \& Bowman, 2009) believe that it is better to sacrifice some of the generality of quantitative research and use qualitative, smaller sample studies which are more appropriate for improving our understanding for researched phenomenon. On the other hand, propositions also have implications for practice by highlighting the areas to which management should orient its efforts. 
Within the dynamic capabilities framework, some researchers assume direct link between dynamic capabilities and performance (e.g., Zollo \& Winter, 2002), whereas some other researchers suggest that dynamic capabilities are necessary but sufficient conditions for competitive advantage and superior performance (e.g., Eisenhardt \& Martin, 2000), thus pointing to indirect link between dynamic capabilities and performance (see also Barreto, 2010). However, we believe that nowadays an orientation toward "dynamics" should be the major orientation of an enterprise where constant sensing and seizing of business opportunities is needed. In order to build and sustain enterprise's dynamics an integral approach toward governance and management of an enterprise is of crucial importance (e.g., Belak \& Duh, 2012; Rüegg-Stürm, 2002). It means that this major orientation should be incorporated in the goals and objectives at all hierarchical levels of management process; that is in enterprise's vision, mission, and strategies as well as in operative goals and objectives of an enterprise. Management endeavor plays a crucial role in defining and implementing this major orientation toward “dynamics". Especially the top management team, which knowledge determines the enterprise's ability to adapt to changes in the environment (e.g., Dixon et al., 2010), plays a crucial role in explaining the necessary organizational changes and creating commitment to the overall dynamic orientation of an enterprise. Therefore, sometimes changes in management team are necessary to increased probability of strategic reorientation (e.g., Dixon et al., 2010).

Some authors (e. g., Barreto, 2010) call attention to significant variations in the literature regarding the kind of external environments that are relevant for dynamic capabilities. Pümpin and Prange (1995) do not address this question explicitly since they understand the demand for enterprise's dynamics as "natural" reaction to the process of enterprise's maturing. Some researchers of dynamic capabilities describe the concept to highly dynamic environments; others see the dynamic capabilities concepts to be of importance also in "moderately dynamic" markets (e.g., Eisenhardt \& Martin, 2000). In this discussion about the character of external environment for applicability of the dynamic capabilities approach we see the problem of the definition of the external environment, especially of the relevant external environment. In this context we see of special importance the Obrecht's (2003) division of enterprise's external environment into the operational (defined by the location where an enterprise do the majority of its operations), market (defined by the markets where an enterprise is active) and cognitive environment (defined by cognitive dimension of entrepreneur or top management of an enterprise). Even though a market environment may be low or moderate dynamic, there can be cognitive environment in which the enterprise (i.e., its managers, entrepreneurs) can trace dynamic changes, especially nowadays in the era of knowledge society and hyper production of information, which demands new mental models to be developed. Also the firm's operative environment can show high dynamics (e.g., political instability, frequent changes of legislation which was and is still characteristic of post-socialist countries) whereas on the other hand the firm's market environment is exhibiting low dynamics.

The dynamic capabilities approach and the concept of a dynamic enterprise both address the same question which Teece (2007) describe as “ ... an extremely seminal and complicated issue: how a business enterprise and its management can first spot the opportunity to earn economic profits, make the decision and institute the discipline to execute on that opportunity, and then stay agile so as to continuously refresh the foundations of its early success, thereby generating economic surpluses” (p. 1347). The question of how to sustain not just technical (internal) but specially the evolutionary (external) fitness (see Teece, 2007, 1321, 1344) or what Kajzer (2003, 163-164) describes as efficiency (according to Drucker (1967) "to do the things right”) and effectiveness (according to Drucker (1967) "to do the right things") should also addresses how to do that in an ethical and credible way taking into consideration the interest of all stakeholders; that means giving the priority to the "Stakeholder value perspective" instead of "Shareholder value perspective (Belak, 2010; Müller-Stewens \& Lechner, 2005).

\section{Conclusions}

We believe that the life cycle concept and the concept of a dynamic enterprise provide useful cognition regarding the demand for a dynamic nature of enterprises and can therefore contribute new insights to the dynamic capabilities approach. We developed eleven propositions within the research presented in this paper which provide basis for development of empirical testing as well as indicating conditions for building and sustaining enterprise's dynamics. The explorations of enterprise's developmental situation (i.e., the presence of life cycle stages' characteristics) and propositions developed are opening a potentially fruitful perspective for analyzing the enterprise's propensity toward dynamics. It is possible to get a diagnosis of an enterprise and to propose suggestions and measures for its improvement. The major orientation of an enterprise toward "dynamics" requires an integral governance and management approach to effectively respond to changes in enterprise's environment. The enterprise's environment should be seen as a composition of operational, market 
and cognitive environment and therefore the future research should take into consideration all three environments when defining the level of environmental dynamism, and not just market dynamism. The future research on enterprise's dynamics and dynamic capabilities should also address the issue of ethics and credibility since the recent crisis is not just a financial and economic crisis but as well as (or especially) the crisis of values.

\section{References}

Ambrosini, V., \& Bowman, C. (2009). What are dynamic capabilities and are they useful construct in strategic management? International Journal of Management Reviews, 11(1), 29-49. http://dx.doi.org/10.1111/j.1468-2370.2008.00251.x

Barney, J., Wright, M., \& Ketchen, D. J. Jr. (2001). The resource-based view of the firm. Ten years after 1991. Journal of Management, 27(6), 625-641. http://dx.doi.org/10.1177/014920630102700601

Barreto, I. (2010). Dynamic Capabilities: A Review of Past Research and an Agenda for the Future. Journal of Management, 36(1), 256-280. http://dx.doi.org/10.1177/0149206309350776

Belak, J., \& Duh, M. (2012). Integral management: key success factors in the MER model. Acta Polytechnica Hungarica, 9(3), 5-26.

Bierly, P. E., \& Daly, P. S. (2007). Alternative Knowledge, Strategies, Competitive Environment, and Organizational Performance in Small Manufacturing Firms. Entrepreneurship Theory and Practice, 31(4), 493-516. http://dx.doi.org/10.1111/j.1540-6520.2007.00185.x

Dixon, S. E. A., Meyer, K. E., \& Day, M. (2010). Stages of Organizational Transformation in Transition Economies: A Dynamic Capabilities Approach. Journal of Management Studies, 47(3), 416-436. http://dx.doi.org/10.1111/j.1467-6486.2009.00856.x

Drucker, P. (1967). The Effective Executive. London: Heinemann.

Eisenhardt, K. M., \& Martin, J. A. (2000). Dynamic capabilities: What are they? Strategic Management Journal, 21(10-11), http://dx.doi.org/10.1002/1097-0266(200010/11)21:10/11<1105::AID-SMJ133>3.0.CO;2-E

1105-1121.

Gibson, C. B., \& Birkinshaw, J. (2004). The antecedents, consequences, and mediating role of organizational ambidexterity. Academy of Management Journal, 47(2), 209-226. http://dx.doi.org/10.2307/20159573

Harreld, J. B., O’Reilly, C. A., \& Tushman, M. L. (2007). Dynamic capabilities at IBM: driving strategy into action. California Management Review, 49(4), 21-43. http://dx.doi.org/10.2307/41166404

Helfat, C. E., \& Peteraf, M. A. (2003). The dynamic resource-based view: capability lifecycle. Strategic Management Journal, 24(10), 997-1010. http://dx.doi.org/10.1002/smj.332

Hoskisson, R. E., Hitt, M. A., Wan, W. P., \& Yiu, D. (1999). Theory and research in strategic management: Swings of a pendulum. Journal of Management, 25(3), 417-456. http://dx.doi.org/10.1177/014920639902500307

Kajzer, S. (2003). Tranzicijske krize v procesu razvoja podjetja/Transitional crisis in the process of the enterprise's development. In Belak, J. (Ed.), Integralni management in razvoj podjetja/Integral management and enterprises development (pp. 160-170). Maribor: Založba MER.

Kraatz, M. S., \& Zajac, E. J. (2001). How organizational resources affect strategic change and performance in turbulent environments: Theory and evidence. Organization Science, 12(5), 632-657. http://dx.doi.org/10.1287/orsc.12.5.632.10088

Lambrecht, J., \& Lievens, J. (2008). Pruning the Family Tree: An Unexplored Path to Family Business Continuity and Family Harmony. Family Business Review, 21(4), 295-313.

March, J. G. (1996). Continuity and change in theories of organizational action. Administrative Science Quarterly, 41(2), 278-287. http://dx.doi.org/10.2307/2393720

March, J. G. (2006). Rationality, foolishness, and adaptive intelligence. Strategic Management Journal, 27(3), 201-214. http://dx.doi.org/10.1002/smj.515

Müller-Stewens, G., \& Lechner, C. (2005). Strategisches Management. Wie strategische Initiativen zum Wandel führen. Stuttgart: Schäffer-Poeschel Verlag. 
Obrecht, J. J. (2003). Strateške razvojne situacije malih in srednje velikih podjetij / Strategic developmental situations of small and medium-sized enterprises. In Belak, J. (Ed.), Integralni management in razvoj podjetja / Integral management and enterprises development (pp. 234-247). Maribor: Založba MER.

O’Reilly, C., \& Tushman, M. (2007). Ambidexterity as a Dynamic Capability: Resolving the Innovator's Dilemma. Research paper No. 1963. Research paper Series. Stanford, Graduate School of Business. Retrieved 17 April 2012 from http://ssrn.com/abstract=978493

Phan, P. H. (2006). Dynamism as a necessary property of entrepreneurial systems. Journal of Business Venturing, 21(2), 149-151. http://dx.doi.org/10.1016/j.jbusvent.2005.04.001

Pümpin, C., \& Prange, J. (1995). Usmerjanje razvoja podjetja. Fazam ustrezno vodenje in obravnavanje kriz/Management of the enterprise's development: management adjusted to stages and dealing with crises (Original: Management der Unternehmensentwicklung: phasengerechte Führung und der Umgang mit Krisen. Frankfurt/Main: Campus Verlag GmbH, 1991). Ljubljana: Gospodarski vestnik.

Rüegg, S. J. (2002). Das neue St. Galler Management-Modell. Bern. Stuttgart, Berlin: Verlag Paul Haupt.

Schreyögg, G., \& Kliesch-Eberl, M. (2007). How dynamic can organizational capabilities be? Towards a dual-process model of capability dynamization. Strategic Management Journal, 28(9), 913-933. http://dx.doi.org/10.1002/smj.613

Simsek, Z., Heavey, C., Veiga, J. F., \& Souder, D. (2009). A typology for aligning organizational ambidexterity's conceptualizations, antecedents, and outcomes. Journal of Management Studies, 46(5), 864-893. http://dx.doi.org/10.1111/j.1467-6486.2009.00841.x

Teece, D. J. (2007). Explicating dynamic capabilities: the nature and microfundations of (sustainable) enterprise performance. Strategic Management Journal, 28(13), 319-1350. http://dx.doi.org/10.1002/smj.640

Teece, D. J., Pisano, G., \& Shuen, A. (1997). Dynamic capabilities and strategic management. Strategic $\begin{array}{lll}\text { Management } & \text { Journal, 509-533. }\end{array}$ http://dx.doi.org/10.1002/(SICI)1097-0266(199708)18:7<509::AID-SMJ882>3.0.CO;2-Z

Wang, C. L., \& Ahmed, P. K. (2007). Dynamic capabilities: A review and research agenda. International Journal of Management Reviews, 9(1), 31-51. http://dx.doi.org/10.1111/j.1468-2370.2007.00201.x

Wang, C. L., \& Rafiq, M. (2012). Ambidextrous Organizational Culture, Contextual Ambidexterity and New Product Innovation: A Comparative Study of UK and Chinese High-Tech Firms. British Journal of Management, 1-19.

Wheelen, T., \& Hunger, J. D. (2012). Strategic Management and Business Policy. Toward Global Sustainability. New Jersey: Pearson.

Wiggins, R. R., \& Ruefli, T. W. (2005). Schumpeter's ghost: Is hypercompetition making the best of times shorter? Strategic Management Journal, 26(10), 887-911. http://dx.doi.org/10.1002/smj.492

Winter, S. G. (2003). Understanding dynamic capabilities. Strategic Management Journal, 24(10), 991-995. http://dx.doi.org/10.1002/smj.492

Zollo, M., \& Winter, S. G. (2002). Deliberate learning and the evolution of dynamic capabilities. Organization Science, 13(3), 339-351. http://dx.doi.org/10.1287/orsc.13.3.339.2780 